\title{
Phenotypic and Genotypic Characterization of Resistance to Macrolides and Lincosamides in Streptococcus agalactiae Isolated from Pregnant Women in Misiones, Argentina
}

\author{
Marina Novosak, ${ }^{1,2}$ Fernando Bobadilla, ${ }^{1,2}$ Osvaldo Delgado, ${ }^{3,4}$ Marta Vergara, ${ }^{1}$ and Margarita Laczeski $i^{1,2,5}$
}

\begin{abstract}
The aim of this work was to determine the susceptibility, molecular profile, and clonal relationship in Streptococcus agalactiae (group B Streptococcus [GBS]) isolated from vaginal-rectal swab samples. We worked with 200 isolates collected from pregnant women between 35 and 37 weeks of gestation. The macrolidelincosamide-streptogramin B $\left(\mathrm{MLS}_{\mathrm{B}}\right)$ resistance phenotypes were determined using the double-disc assay. Susceptibility to erythromycin (ERI) and clindamycin (CLI) was performed with the E-test. Resistance genes ermB and ermTR were detected by polymerase chain reaction. Clonal studies were performed using the random amplification of polymorphic DNA. Twelve $(6 \%)$ of the isolates were resistant to ERI and $10(5 \%)$ of them to CLI. Fifty percent of the resistant strains corresponded to serotype III, 25\% to serotype V, and the remaining $25 \%$ to serotype Ia, II, and nontypeable strains. The $\mathrm{cMLS}_{\mathrm{B}}$ phenotype was detected in eight strains (66.67\%) and the $\mathrm{iMLS}_{\mathrm{B}}$ phenotype in four (33.33\%). The minimum inhibitory concentration values were between 1.5 and $16 \mu \mathrm{g} / \mathrm{mL}$ for ERI, and between 1 and $32 \mu \mathrm{g} / \mathrm{mL}$ for CLI. Out of the 25 strains susceptible to ERI and CLI, the presence of the $e r m B$ gene was detected in eight of them and the ermTR gene in one strain. The ermB gene was detected in the 12 strains that initially had some macrolide resistance phenotype. The ermTR gene was detected in three out of the four strains with the $\mathrm{iMLS}_{\mathrm{B}}$ phenotype. The resistance to macrolides in the province of Misiones is due to multiclonal spread. The phenotypic and genotypic characterization of macrolide resistance in GBS strains are crucial to contribute to the correct intrapartum prophylactic antibiotic therapy of allergic pregnant women and the epidemiological surveillance of these strains.
\end{abstract}

Keywords: Streptococcus agalactiae, antibiotic resistance, E-test, D-test, RAPD

\section{Introduction}

STEPtococcus agalactiae, also called group B Streptococcus (GBS), was initially recognized in 1887 by Nocard and Mollereau as an infectious agent of bovine mastitis. ${ }^{1}$ In 1879 , Pasteur detected similar microorganisms in the blood of a patient with puerperal sepsis. It follows that these were the first GBS identified. These microorganisms were isolated by Lancefield and Hare from vaginal cultures of asymptomatic postpartum women in 1935 and identified for the first time as human pathogens that caused three cases of fatal puerperal fever in $1938 .^{2}$

During the following years, GBS was not isolated from human infections. In 1970, it became relevant as an etio- logical agent, not only in adults as an emerging disease in nursing homes and intensive care units, which caused a change of paradigm in the epidemiological control of $\mathrm{GBS}^{3}$ but also in neonates, in which it still is the leading cause of severe invasive infections, as well as in infants younger than 3 months. Meningitis, pneumonia and sepsis, the major infections in these children, are described as the most serious illnesses that individuals can suffer in their first hours of life. ${ }^{4}$ It is important to note that GBS and Escherichia coli are responsible for $23 \%$ and $42 \%$, respectively, of bacteremias in children younger than 90 days. ${ }^{5}$ Statistics indicate that $50 \%$ of children born to mothers carrying GBS will be colonized by this microorganism. Out of these children, $1 \%$ will develop invasive

\footnotetext{
${ }^{1}$ Cátedra de Bacteriología, Departamento de Microbiología, Facultad de Ciencias Exactas, Químicas y Naturales (FCEQyN), Universidad Nacional de Misiones (UNaM), Misiones, Argentina.

${ }^{2}$ Consejo Nacional de Investigaciones Científicas y Técnicas (CONICET), Buenos Aires, Argentina.

${ }^{3}$ Planta Piloto de Procesos Industriales Microbiológicos (PROIMI-CONICET), Tucumán, Argentina.

${ }^{4}$ Centro de Biología Molecular y Biotecnología (CEBIOTEC), Facultad de Ciencias Exactas y Naturales (FACEN), Universidad Nacional de Catamarca (UNCa), Catamarca, Argentina.

${ }^{5}$ Laboratorio de Biotecnología Molecular, Instituto de Biotecnología Misiones “Dra. María Ebe Reca” (InBioMis), FCEQyN, UNaM, Misiones, Argentina.
} 
disease. As a result of preventive efforts, the overall incidence of invasive neonatal GBS infection has declined significantly over the past few years. ${ }^{6}$

Streptococcus agalactiae has a rhamnose-glucosamine polymer bound to the peptidoglycan layer, an antigen combination that characterizes it as the only member of group B. Classification within the 10 existing serotypes (Ia, Ib, II, III, IV, V, VI, VII, VIII, and IX) is due to the different capsular dispositions of glucose, galactose, $\mathrm{N}$-acetylglucosamine, and acid $N$-acetylneuraminic acid. ${ }^{7}$ The prevalence of the different capsular serotypes of group B streptococci varies over time and may differ from place to place. Epidemiological surveillance of this distribution is important for the choice of conjugate vaccines currently under evaluation to achieve adequate coverage. ${ }^{8}$

To prevent neonatal infection, the Center for Disease Prevention and Control, Atlanta, recommends testing for GBS in all pregnant women between 35 and 37 weeks of gestation by vaginal (anterior third) and anorectal swabbing. ${ }^{3}$ Although colonization in the first weeks of pregnancy is not predictive of the subsequent risk of neonatal sepsis, determination of the presence of GBS at any concentration, and even at any stage of pregnancy, is considered one of the factors determining intrapartum prophylaxis, without the need to perform screening at weeks $35-37 .{ }^{9}$ Colonization during pregnancy does not necessarily imply colonization in subsequent pregnancies; therefore, a culture must be performed at each new gestation. As a result of these preventive efforts, the overall incidence of invasive neonatal GBS infection has declined significantly all over the world over the past 15 years. $^{3}$

At present, intrapartum prophylactic antibiotic therapy is implemented in women colonized by GBS up to 5 weeks before delivery, whether or not they present some of the risk factors mentioned above. Penicillin is the first-line drug for the treatment of GBS infections and for intrapartum prophylaxis. ${ }^{10}$ However, some researchers have demonstrated microorganism tolerance to these antibiotics by both phenotypic and molecular approaches. This property was assigned to the substitution of amino acids adjacent to the conserved SSN and KSG domains of the $2 \mathrm{X}$ penicillin binding protein (PBP 2X), suggesting that it contributes to treatment failure. ${ }^{11}$

Because of the above mechanisms and the existence of patients who are allergic to penicillin, it is necessary to use alternative antimicrobials such as macrolides and lincosamides, a group of antibiotics structurally characterized by a macrocyclic ring bound to two sugars. Among them, erythromycin (ERI) and clindamycin (CLI) are used as second-choice antibiotics in these cases. The mechanism of action of these antibiotics is the binding to the 50S subunit of bacterial ribosomes, thus inhibiting protein synthesis. ${ }^{12}$

In recent years, there has been an increase in antibiotic resistance of the macrolide-lincosamide-streptogramin B $\left(\mathrm{MLS}_{\mathrm{B}}\right)$ group in GBS strains. The two main mechanisms of resistance are modifying the target site and active efflux. ${ }^{13}$ The target modification above occurs because erm genes (erythromycin ribosomal methylase), ermB and ermA (ermTR subclass), mediate the methylation of the $23 \mathrm{~S}$ subunit of rRNA, thus causing a conformational change in the prokaryotic ribosome and blocking the binding of macrolides, lincosamides, and streptogramin B to their binding site in the $50 \mathrm{~S}$ subunit. ${ }^{14}$
The ability of GBS to generate resistance to ERI and CLI has two variables: the constitutive resistance $\mathrm{cMLS}_{\mathrm{B}}$ and the inducible $i M L S_{\mathrm{B}}$, related to the expression of ermB gene and ermTR, respectively. The constitutive variable presents a high level of resistance to any antimicrobial of the $M_{L} S_{B}$ group. In contrast, the inducible way presents resistance to macrolides of 14 atoms (ERI) and 15 atoms (azithromycin), and in vitro susceptibility to macrolides of 16 atoms, CLI, and streptogramins B. In $\mathrm{iMLS}_{\mathrm{B}}$ strains, the expression of the erm genes is strongly induced by ERI, whereas CLI is a weak inducer that acts slowly, so strains with $\mathrm{iMLS}_{\mathrm{B}}$ resistance appear in vitro susceptibility to CLI, but, when used clinically, in vivo self-induced resistance occurs with consequent therapeutic failure.

The double-disc test (D-test), recommended by the Clinical and Laboratory Standards Institute (CLSI) ${ }^{15}$ to be used for the detection of the $\mathrm{iMLS}_{\mathrm{B}}$ mechanism as a test of the phenotype expression, is of great utility in presaging the mutation toward in vivo constitutive resistance. ${ }^{16}$ These mechanisms cannot be detected using either conventional disk diffusion methods or by standard broth or plate dilution methods.

The World Health Organization recommends surveillance of antibiotic susceptibility and contribution to the knowledge of the dissemination of resistance mechanisms or clones, bearing these characteristics to define new treatment strategies in each region. Several epidemiological studies carried out on GBS isolates are based on serotyping techniques; however, these traditional procedures have both low discriminatory power and low reproducibility under different environmental or culture conditions, as well as the disadvantage of the existence of nontyping strains. ${ }^{17}$ Over the last two decades, different groups have developed molecular techniques to study genetic diversity among closely related organisms, such as restriction fragment length polymorphisms, pulsed field gel electrophoresis, electrophoresis of multilocus enzymes, and random amplification of polymorphic DNA (RAPD), which have been used effectively to determine subtypes of isolates of human origin. ${ }^{18}$

In recent years, the RAPD technique has been used extensively for the determination of the epidemiological relationship between GBS isolates. Genetic mapping using the RAPD technique has numerous advantages over other methods, for example, the use of "universal" primers for the analysis of a wide variety of species. Preliminary work, such as sequencing or cloning by DNA probes, is not required, thus optimizing the time to obtain results and research costs. ${ }^{19}$

From the epidemiological point of view, it is important to improve the characterization of the resistance to macrolides and lincosamides of GBS so as to define whether the observed resistance is due to dispersion of a specific clone, or to the acquisition of various resistance mechanisms of different clones. Therefore, the aim of this work was to determine the susceptibility to ERI and CLI, molecular profile, and clonal relationship in Streptococcus agalactiae isolated from vaginal-rectal swab samples collected from women at 35 to 37 weeks of gestational age attending the "Ramón Madariaga" Central Hospital and peripheral Primary Health Care centers during the January 2004 to December 2014 period. 


\section{Materials and Methods}

\section{Bacterial strains}

A total of 200 isolates recovered from vaginal-rectal swab samples were collected from women at 35-37 weeks of gestational age attending either the "Ramón Madariaga" Central Hospital or peripheral Primary Health Care centers from Misiones province, Argentina. The swabs were placed in Stuart transport media (Ventura Transystem-Medica-Tec Argentina) and transported to the laboratory at room temperature for microbiology analysis and determination of the serotype. ${ }^{20}$ The isolates were kept in skim milk at $20 \%$ and at $-80^{\circ} \mathrm{C}$. $^{21}$

\section{Susceptibility tests by diffusion}

The $\mathrm{MLS}_{\mathrm{B}}$ resistance phenotypes were determined using the D-test assay with ERI $(15 \mu \mathrm{g})$ and CLI $(2 \mu \mathrm{g})$ discs supplied by Britania (Argentina), according to the recommendations and interpretation of the CLSI. ${ }^{15}$

\section{Determination of minimum inhibitory concentration}

Susceptibility to ERI and CLI was performed with the E-test by using strips provided by Oxoid (United Kingdom) and BioMérieux (Marcy-l'Etoile, France), respectively. The results were interpreted according to CLSI recommendations. ${ }^{15}$ The Staphylococcus aureus ATCC 25923 strain was used as control.

\section{Molecular detection of macrolide resistance genes}

Isolates that showed resistance phenotypes with the diffusion technique and other 25 isolates that were susceptible to ERI and CLI were selected. Resistance genes ermB and ermTR were detected by polymerase chain reaction (PCR). ${ }^{22}$ The primers used to detect resistance genes were designed with the Primer3 version 0.4.0 software ${ }^{23}$ using complete sequences for each gene available at the National Center for Biotechnology Information (NCBI). Their respective sequence, and the melting temperature (TM) used during the PCR reaction are shown in Table 1 . Whole DNA was obtained according to the protocol described by Sambrook and Rusell $^{24}$ modified by Cariaga Martinez and Zapata. ${ }^{25}$ The sequencing of the PCR products was performed by Macrogen. Positive controls were provided by the Antimicrobial Service of the Argentine Reference Institute "Dr. Carlos G. Malbrán (National Institute of Infectious Diseases-A.N.L.I.S.)"': Streptococcus pneumoniae AZ1: Gene $\mathrm{ermB}^{26}$ and Streptococcus agalactiae 6394: Gen ermTR. ${ }^{27}$ Besides, a negative control, consisting of the same reaction mixture but with water instead of template DNA, was included in each run.

\section{PCR amplification technique}

The PCR was performed with $20 \mathrm{ng}$ DNA at a final volume of $20 \mu \mathrm{L}$ containing $1 \times$ Taq DNA polymerase buffer $(10 \times$ :
$500 \mathrm{mM} \mathrm{KCl}$ and $100 \mathrm{mM}$ Tris- $\mathrm{HCl}, \mathrm{pH} 9.0$ at $25^{\circ} \mathrm{C} ; 1 \%$ Triton $\left.{ }^{\circledR} \mathrm{X}-100\right), 200 \mu \mathrm{M}$ of each dNTP, $10 \mathrm{pmol}$ of each primer, and $0.5 \mathrm{U}$ of the Taq DNA polymerase enzyme (Inbio Highway, Argentina). The optimization of the technique (setup for each gene) was performed with concentrations of $\mathrm{MgCl}_{2}$ (Taq DNA polymerase co-enzyme) of $1.5,2$, and $3 \mathrm{mM}$. The cycling schedule applied to each PCR reaction was performed by predenaturation at $94^{\circ} \mathrm{C}$ for $2 \mathrm{~min}$ followed by 30 cycles $\left(30 \mathrm{sec}\right.$ at $94^{\circ} \mathrm{C}, 60 \mathrm{sec}$ at $50^{\circ} \mathrm{C}$, and $60 \mathrm{sec}$ at $72^{\circ} \mathrm{C}$ ), and final elongation at $72^{\circ} \mathrm{C}$ for $2 \mathrm{~min}$, in a Multigene TM II thermocycler (Labnet International, Inc.). Amplicons were visualized on $2 \%(\mathrm{w} / \mathrm{v})$ agarose gels and photographed with a Cannon Power Shot G10 digital camera. The TM used varied according to the primer used for each virulence gene (Table 1).

\section{DNA sequence analysis}

The sequences obtained were analyzed in silica with a BLASTn algorithm available at NCBI. The analysis was based on similarity to sequences aligned in the BLAST search.

\section{Nucleotide sequence accession numbers}

The nucleotide sequences reported in this article have been submitted to the GenBank/EMBL sequence database and assigned accession No. MG252535 (for the $\mathrm{ermB}$ gene from Streptococcus agalactiae strain 369/10) and MG252536 (for the ermTR gene from Streptococcus agalactiae strain 1090).

\section{Statistical analysis of the results obtained}

The results were statistically analyzed with the SPSS version 19 software using the Chi-square test when the value in each box exceeded 5 and Fisher's exact test when it was lower than 5 to evaluate if there were significant differences. The confidence interval for proportions was calculated using the formula $p \pm \mathrm{z} \alpha / 2[p(1-p) / n] 1 / 2$, where $p$ is the observed proportion for each variable and $n$ the total number of individuals analyzed. We considered that for dichotomous populations with a success rate $\pi$, the point estimator of the parameter is the sample success ratio $p$, which coincides with the sample mean when the characteristic that is considered success is coded as 1 , while the one considered not successful is coded as 0 . For a moderately large sample size, the $p$-statistic has an approximately normal distribution.

\section{RAPD technique}

Clonal studies were performed using the RAPD-RAPD technique. $^{18}$ The primers OPS11 (5'AGTCGGGTGG3'), OPB17 (5'AGGGAACGAG3'), and OPB18 (5'CCACAGC $\left.\mathrm{AGT}^{\prime}\right)^{28}$ were selected. To evaluate the utility of each primer to select nongenetically related isolates, the Hunter

Table 1. Sequences of Data Used in Polymerase Chain Reaction to Amplify Resistance Genes In STREPTOCOCCUS aGalactiaE Strains

\begin{tabular}{lllcc}
\hline Genes & \multicolumn{1}{c}{ Sense $5^{\prime}-3^{\prime}$} & Antisense $5^{\prime}-3^{\prime}$ & Amplicon $($ bp $)$ & Tm $\left({ }^{\circ} \mathrm{C}\right)$ \\
\hline ermB & GAAAAAGTACTCAACCAAATA & AGTAATGGTACTTAAATTGTTTAC & 639 & 50 \\
ermTR & TTGGGTCAGGAAAAGGA & GGGTGAAAATATGCTCG & 385 & 50
\end{tabular}


and Gaston formula ${ }^{29}$ was used to return the Index of Discrimination $(D)$, which must be $>0.90$ for the interpretation of reliable typing results.

\section{RAPD amplification}

The PCR reaction was performed with $50 \mathrm{ng}$ DNA in a final volume of $50 \mu \mathrm{L}$ containing $1 \times$ of Taq DNA polymerase buffer $(10 \times: 500 \mathrm{mM} \mathrm{KCl}, 100 \mathrm{mM}$ Tris- $\mathrm{HCl}$, pH 9.0 at $25^{\circ} \mathrm{C}$, and $1 \%$ Triton $\left.{ }^{\circledR} \mathrm{X}-100\right), 100 \mathrm{mM}$ of each dNTP, $0.4 \mathrm{mM}$ of each primer, and $2.5 \mathrm{U}$ of the enzyme Taq DNA polymerase (Inbio Highway).

A concentration of $\mathrm{MgCl}_{2}$ of $2.5 \mathrm{mM}$ was used, the cycling conditions being as follows: $5 \mathrm{~min}$ at $94^{\circ} \mathrm{C} ; 40$ cycles of $1 \mathrm{~min}$ at $94^{\circ} \mathrm{C}, 1 \mathrm{~min}$ at $36^{\circ} \mathrm{C}$, and $1 \mathrm{~min}$ at $72^{\circ} \mathrm{C}$; and $5 \mathrm{~min}$ at $72^{\circ} \mathrm{C}$. The electrophoretic run was performed on $1.2 \%$ agarose gel at $100 \mathrm{~V}$ for $3 \mathrm{hr}$. The gels were stained with GelRed ${ }^{\circledR}$, in an electrophoretic cell with subsequent observation of the bands in a UV transilluminator.

\section{Analysis of RAPD data}

The band patterns obtained were normalized and compared to each other by visual inspection. On the basis of migration distance, the size of the different bands was measured and interpolated at the corresponding molecular weight marker using the GraphPad Prism software. Different patterns were considered those differing in more than four bands.

Each RAPD profile was analyzed for the presence (1) or absence (0) of each defined band. The binary matrix obtained was analyzed using Software Treecon $1.3 \mathrm{~b}$, which generated a dendrogram or tree of similarity to establish the relationships between the studied strains. We used the Nei and $\mathrm{Li}$ algorithm to calculate genetic distances. The grouping analysis was performed by unweighted pair group method with arithmetic mean clustering, and its robustness was corroborated by a bootstrap of 1,000 replicates. In addition, the reference strain $S$. agalactiae SS 615 well char- acterized by the Center for Disease Control and Prevention (Atlanta, GA) was included as external control. ${ }^{28}$

\section{Results}

Susceptibility tests for macrolides and lincosamides using the diffusion method

Out of the 200 isolates studied, $12(6 \%)$ of the isolates were resistant to ERI and $10(5 \%)$ of them to CLI. Fifty percent of the resistant strains corresponded to serotype III, $25 \%$ to serotype $\mathrm{V}$, and the remaining $25 \%$ to serotype Ia, II, and nontypeable (NT) strains. Twelve strains with the following phenotypes were detected with the D-test method: the $\mathrm{cMLS}_{\mathrm{B}}$ phenotype in eight strains $(66.67 \%)$ and the $\mathrm{iMLS}_{\mathrm{B}}$ phenotype in four $(33.33 \%)$ (Table 2).

Fifty percent of the strains presenting the $\mathrm{CMLS}_{\mathrm{B}}$ phenotype corresponded to serotype III. All other serotypes detected for this phenotype were presented individually: Ia, II, and V and one NT strain. The eight isolates detected as $\mathrm{cMLS}_{\mathrm{B}}$ phenotype also indicated concomitant resistance to CLI. Out of the strains with the iMLS $_{B}$ phenotype, $60 \%$ corresponded to serotype $\mathrm{V}, 20 \%$ to serotype Ia, and the remaining $20 \%$ to serotype III (Table 2 ).

Serotype Ia, the one most frequently isolated in this study, had susceptibility close to $100 \%$ for ERI and CLI. Only one out of the 12 resistant strains belonging to this serotype was found, showing $\mathrm{cMLS}_{\mathrm{B}}$ phenotype. On the other hand, no resistance to macrolides was detected in serotype Ib and IX strains. No isolation presented phenotype M (Table 2).

\section{Determination of minimum inhibitory concentration}

Our results were correlated in the presence of $\mathrm{MLS}_{\mathrm{B}}$ phenotype, both constitutively and inducible by both methods, diffusion (by D-test) and dilution by determination of the minimum inhibitory concentration (MIC).

The constitutive resistance phenotypes $\left(\mathrm{cMLS}_{\mathrm{B}}\right)$ found were confirmed by MIC, with moderate resistance values for resistant strains. Our MIC values were between 1.5 and

Table 2. Strains of Colonizing Streptococcus agalactiae with Resistance to ERythromycin and Clindamycin: Serotypes, Macrolide Susceptibility Test Results with D-Test and Minimum Inhibitory Concentration, and the Presence of ermB and ermTR Genes by Polymerase Chain Reaction

\begin{tabular}{|c|c|c|c|c|c|c|c|c|c|}
\hline \multirow[b]{2}{*}{$I D$} & \multirow[b]{2}{*}{ Serotype } & \multicolumn{2}{|c|}{ Diffusion (mm) } & \multirow[b]{2}{*}{ D-test } & \multirow[b]{2}{*}{ Phenotype } & \multicolumn{2}{|c|}{$M I C(\mu g / m L)$} & \multicolumn{2}{|c|}{ Resistance genes (PCR) } \\
\hline & & ERI & $C L I$ & & & ERI & $C L I$ & ermB & ermTR \\
\hline $141 / \mathrm{P}$ & III & 7 & 7 & N/D & $\mathrm{cMLS}_{\mathrm{B}}$ & 2 & 1 & + & - \\
\hline 962/P & NT & 7 & 6 & N/D & $\mathrm{cMLS}_{\mathrm{B}}$ & 4 & 8 & + & - \\
\hline 1075/P & III & 6 & 19 & Positive & $\mathrm{iMLS}_{\mathrm{B}}$ & 2 & 2 & + & - \\
\hline 1090/P & V & 11 & 22 & Positive & $\mathrm{iMLS}_{\mathrm{B}}$ & 2 & $\leq 0.25$ & + & + \\
\hline 1337/P & V & 7 & 8 & N/D & $\mathrm{cMLS}_{\mathrm{B}}$ & 2 & 2 & + & + \\
\hline $1375 / \mathrm{P}$ & Ia & 6 & 6 & N/D & $\mathrm{cMLS}_{\mathrm{B}}$ & 1.5 & 32 & + & + \\
\hline $8 / 10$ & III & 7 & 8 & N/D & $\mathrm{cMLS}_{\mathrm{B}}$ & 2 & 2 & + & - \\
\hline $128 / 10$ & III & 6 & 6 & N/D & $\mathrm{cMLS}_{\mathrm{B}}$ & 2 & 2 & + & - \\
\hline $137 / 10$ & III & 12 & 12 & Negative & $\mathrm{cMLS}_{\mathrm{B}}$ & 4 & 1 & + & - \\
\hline $369 / 10$ & V & 6 & 20 & Positive & $\mathrm{iMLS}_{\mathrm{B}}$ & 16 & 0.094 & + & + \\
\hline $505 / 10$ & II & 15 & 11 & Negative & $\mathrm{cMLS}_{\mathrm{B}}$ & 2 & 2 & + & - \\
\hline 36VR & III & 12 & 23 & Positive & $\mathrm{iMLS}_{\mathrm{B}}$ & 4 & 4 & + & + \\
\hline
\end{tabular}

ID, identification number of the Bacteriology Laboratory of the National University of Misiones; D-test, double-disc diffusion test for the detection of macrolide resistance phenotypes; ERI, erythromycin; CLI, clindamycin; $\mathrm{MLS}_{\mathrm{B}}$, macrolide-lincosamide-streptogramin B; $\mathrm{iMLS}_{\mathrm{B}}$, inducible phenotype; $\mathrm{cMLS}_{\mathrm{B}}$, constitutive phenotype; MIC, minimum inhibitory concentration; N/D, not detected; +, presence; - , absence; NT, nontypeable. 
A

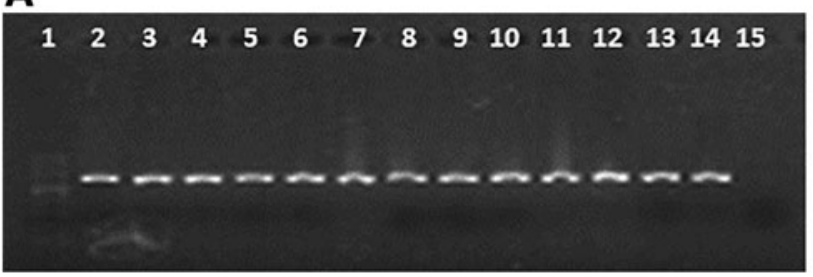

B

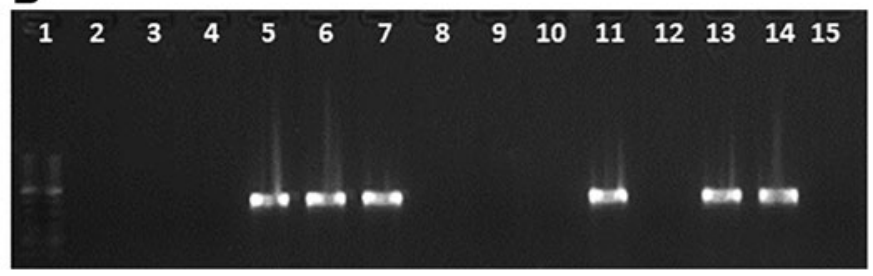

FIG. 1. Macrolide resistance genes. Two percent agarose gel electrophoresis of the polymerase chain reaction products for the genes: (A) ermB and (B) ermTR. First lane, molecular weight marker, DNA marker (D0017) 100-1,000 bp (Inbio Highway, Argentina); lanes 2-13 strains Streptococcus agalactiae (group B Streptococcus) 141, 962, 1075, 1090, 1337, 1375, 8/10, 128/10, 137/10, 369/10, 505/10, and 36VR; lane 14 positive control (Streptococcus pneumoniae AZ1 for ermB gene and Streptococcus agalactiae 6394 for ermTR gene); last lane, negative control.

$16 \mu \mathrm{g} / \mathrm{mL}$ for ERI, and between 1 and $32 \mu \mathrm{g} / \mathrm{mL}$ for CLI. Only two of the inducible phenotypes $\left(\mathrm{iMLS}_{\mathrm{B}}\right)$ detected in our study were confirmed by E-test (Table 2).

\section{Molecular detection of gene resistance to macrolides and lincosamides}

PCR amplification technique. The PCR technique setup for each primer used was achieved with the following concentrations of $\mathrm{MgCl}_{2}: 1.5 \mathrm{mM}$ for ermTR and $3 \mathrm{mM}$ for ermB.

\section{Resistance genes}

Genes ermB and ermTR. Using the primers listed in Table 1, fragments of size 615 and $360 \mathrm{bp}$ were obtained for the ermB and ermTR genes, respectively (Fig. 1).
The ermB gene was detected in all constitutive phenotypes, while the ermTR gene was found in two of them. In the inducible phenotypes, both genes studied were detected.

Analyzing each gene investigated individually, we observed that

- The ermB gene was detected in the 12 strains that initially had some macrolide resistance phenotype.

- The ermTR gene was detected in three out of the four strains with the iMLS $_{\mathrm{B}}$ phenotype.

Out of the 25 strains susceptible to ERI and CLI by diffusion and MIC susceptibility tests, the presence of the $\mathrm{ermB}$ gene was detected in 8 of them and the ermTR gene in one strain (Table 3).

Table 3. Streptococcus agalactiae Colonizing Strains: Serotypes, Macrolide Susceptibility Test Results with D-Test and Minimum Inhibitory Concentration, and the Presence of ermB and ERmTR Genes By Polymerase Chain Reaction

\begin{tabular}{|c|c|c|c|c|c|c|c|c|c|}
\hline \multirow[b]{2}{*}{$I D$} & \multirow[b]{2}{*}{ Serotype } & \multicolumn{2}{|c|}{ Diffusion (mm) } & \multirow[b]{2}{*}{$D$-test } & \multirow[b]{2}{*}{ Phenotype } & \multicolumn{2}{|c|}{$M I C(\mu g / m L)$} & \multicolumn{2}{|c|}{ Resistance genes (PCR) } \\
\hline & & $E R I$ & $C L I$ & & & ERI & $C L I$ & ermB & ermTR \\
\hline $23 / 04$ & Ia & 25 & 24 & Negative & N/D & 0.12 & 0.064 & + & - \\
\hline $53 / 04$ & $\mathrm{Ib}$ & 24 & 22 & Negative & N/D & 0.15 & 0.047 & - & - \\
\hline $6 / \mathrm{P}$ & II & 30 & 29 & Negative & N/D & 0.06 & 0.034 & - & - \\
\hline $10 / \mathrm{P}$ & III & 24 & 23 & Negative & N/D & 0.003 & 0.032 & + & - \\
\hline $97 / \mathrm{P}$ & III & 24 & 24 & Negative & N/D & 0.12 & 0.064 & - & - \\
\hline $122 / \mathrm{P}$ & NT & 29 & 27 & Negative & N/D & 0.06 & 0.064 & - & - \\
\hline $213 / \mathrm{P}$ & Ia & 22 & 22 & Negative & N/D & 0.06 & 0.064 & - & - \\
\hline $330 / \mathrm{P}$ & III & 26 & 26 & Negative & N/D & 0.06 & 0.094 & + & - \\
\hline 338/P & NT & 28 & 27 & Negative & $\mathrm{N} / \mathrm{D}$ & 0.12 & 0.064 & - & - \\
\hline $835 / \mathrm{P}$ & Ia & 28 & 31 & Negative & $\mathrm{N} / \mathrm{D}$ & 0.06 & 0.064 & - & - \\
\hline $883 / \mathrm{P}$ & Ia & 30 & 27 & Negative & N/D & 0.06 & 0.064 & + & - \\
\hline $901 / \mathrm{P}$ & II & 39 & 40 & Negative & N/D & 0.12 & 0.094 & - & - \\
\hline $934 / \mathrm{P}$ & II & 32 & 30 & Negative & N/D & 0.12 & 0.064 & - & - \\
\hline $1080 / \mathrm{P}$ & NT & 29 & 32 & Negative & N/D & 0.06 & 0.032 & + & - \\
\hline $1155 / \mathrm{P}$ & Ia & 26 & 28 & Negative & N/D & 0.003 & 0.032 & + & - \\
\hline $1265 / \mathrm{P}$ & Ia & 22 & 22 & Negative & N/D & 0.12 & 0.064 & - & - \\
\hline $1297 / \mathrm{P}$ & $\mathrm{Ib}$ & 24 & 26 & Negative & N/D & 0.06 & 0.064 & - & - \\
\hline $459 / \mathrm{P}$ & II & 28 & 27 & Negative & N/D & 0.06 & 0.094 & - & - \\
\hline $1485 / \mathrm{P}$ & II & 25 & 28 & Negative & N/D & 0.12 & 0.064 & - & + \\
\hline $\mathrm{A} 6 / \mathrm{P}$ & $\mathrm{Ia}$ & 23 & 22 & Negative & N/D & 0.06 & 0.064 & + & - \\
\hline $\mathrm{A} 10 / \mathrm{P}$ & II & 24 & 24 & Negative & $\mathrm{N} / \mathrm{D}$ & 0.06 & 0.064 & - & - \\
\hline $91 / 10$ & $\mathrm{Ia}$ & 22 & 23 & Negative & N/D & 0.12 & 0.094 & - & - \\
\hline $182 / 10$ & $\mathrm{Ib}$ & 24 & 26 & Negative & N/D & 0.12 & 0.064 & - & - \\
\hline $312 / 10$ & Ia & 26 & 25 & Negative & N/D & 0.15 & 0.064 & + & - \\
\hline $486 / 10$ & II & 26 & 25 & Negative & N/D & 0.12 & 0.062 & - & - \\
\hline
\end{tabular}

+ , presence; -, absence. 
Bioinformatics analysis of the nucleotide sequences obtained

The PCR products obtained for each gene were sequenced and analyzed bioinformatically using the BLASTn algorithm.

The search result showed $99 \%$ identity with ermB (GenBank No. CP007572.1) and ermTR (GenBank No. CP007631.2) genes.

\section{RAPD technique}

A discrimination index equal to one $(D=1)$ for the OPS11 primer was obtained. The ability to differentiate epidemiologically GBS strains was also evaluated with primers OPB17 and OPB18, but it was not possible to discriminate conclusive patterns, for both primers, $D=0.84$ was obtained. After the selection of the primer, the RAPD was performed with the 12 isolates that showed phenotypes of resistance to ERI and CLI. A maximum distance value of $20 \%$ to consider the isolates as a single clone was established a priori. The 12 isolates were divided into 12 amplification profiles whose distances range from $47 \%$ to $100 \%$. Only two clusters $(137 / 10,141 / \mathrm{P}$ and 128/10, 08/10) were defined with $<55 \%$ distance. Strains 1090/P and 1375/P were not pooled and presented distance values greater than $95 \%$. The external group presented no coincidence with the studied strains, their distance being $100 \%$. There was no correlation between the clusters and the serotypes expressed by neither each strain nor any relationship to the resistance phenotype. Due to the high degree of distance between the isolates, the 12 isolates studied belonged to 12 different clones (Fig. 2).

\section{Discussion}

In this study, we found low rates of isolates resistant to macrolides. We found no elevated macrolide resistance associated with serotype V. Serotype III presented the highest resistance. Our results are similar to Lopardo et al. ${ }^{30}$ for Argentina, which indicate 5.2\% invasive isolates. Souza et al. $^{31}$ reported $4.7 \%$ resistance to ERI in Brazil, a country that also borders Argentina, especially our province, while other researchers showed values of $4.1 \%$ and $3 \%$ of resistance for ERI and CLI, respectively. ${ }^{14}$

However, higher rates of resistance have been found in other geographical areas in South and North America. Abarzúa et al. $^{32}$ reported $17.3 \%$ of ERI resistance and $13.1 \%$ of CLI resistance in GBS strains in Chile, while Back et al. reported resistance of $50.7 \%$ for ERI and $38.4 \%$ for CLI in United States. ${ }^{33}$ On the other hand, a study carried out in Spain reported $20.7 \%$ of ERI resistance and $17.6 \%$ of CLI resistance. ${ }^{34}$

In Asia, high values of macrolide resistance were reported: $50 \%$ for Taiwan according to Wang et al. ${ }^{35}$ and $50 \%$ for Korea according to Lee et al. ${ }^{36}$

Given the high variability of data already available from both colonizing and invasive strains in different geographic areas, the probability of inadequate prophylaxis with these antimicrobials or the need for alternative treatments in these patients has been raised. These differences in the levels of susceptibility to ERI and CLI may be due to the policies applied in the use of antimicrobials in the different regions.

About the relationship between resistant profile and the serotypes detected, our results were similar to those published

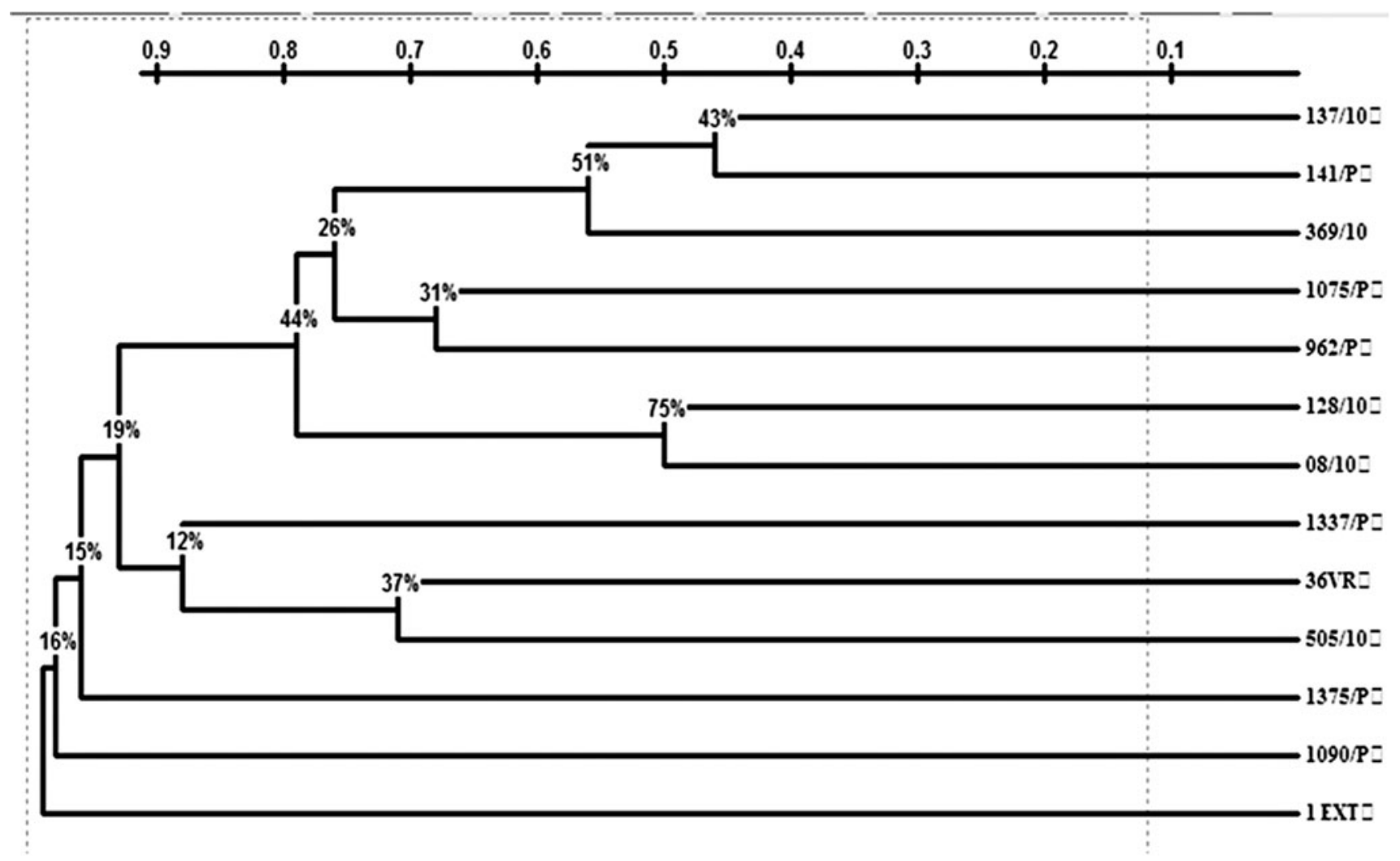

FIG. 2. Dendrogram showing the clonal relationships between 12 strains of macrolide-resistant Streptococcus agalactiae isolated in Misiones province. 1 EXT (External control: Reference strain S. agalactie ss 625). 
by researchers that indicate serotype III as prevalent in its association with macrolide resistance. ${ }^{37}$ However, they differed from the results obtained by Wang et al. ${ }^{35}$ that show for Taiwan, other serotypes such as IV and Ib, which surpass serotype III in its relationship to resistance to macrolides. This not only shows geographical variability but also the importance of implementing different antimicrobial policies.

Fröhlicher et al. $^{38}$ mentioned serotype $\mathrm{V}$ associated with macrolide resistance in the first place. Different studies have reported that serotype $\mathrm{V}$ emerged recently as a cause of human disease; they have also reported that there is a high likelihood of acquiring macrolide resistance and dissemination. ${ }^{39,40}$ In our study, serotype $\mathrm{V}$ appears after serotype III in relationship to resistance to the above antibiotics.

Serotype V, initially identified as NT, was isolated in the United States in 1976. At the time of the disposal of the corresponding sera, it was identified as serotype V. In1980, it was recognized as a common serotype, not only in the United States but also in France, Indonesia, Japan, and Sweden, among other countries. Its isolation from invasive disease was also frequent in nonpregnant adults, in pregnant women, and infants with early infection. ${ }^{41}$

Given the ethnic homogeneity of our patients, we cannot associate our findings with the ethnicity of pregnant women, in contrast with Chohan et al., ${ }^{42}$ who found an important association between CLI and ERI resistance in Caucasian women, which was higher than in African, American, or Hispanic women. Other authors such as Manning ${ }^{43}$ reported associations between high resistance to CLI and black women.

In this study, we found the macrolide resistance mechanism $\mathrm{cMLS}_{\mathrm{B}}$ associated with the $\mathrm{ermB}$ gene with greater accuracy. The examination of the macrolide resistance phenotypes detected by diffusion methods is similar to that published by Lopardo et al. ${ }^{30}$ for Argentina and Wu et al. ${ }^{44}$ These authors also found the $\mathrm{cMLS}_{\mathrm{B}}$ phenotype more frequently. Given the prevalence of the erm gene, susceptibility to CLI should be reported based on the D-test results.

At present, the emergence of strains resistant to ERI and $\mathrm{CLI}^{32}$ is well known. The values of resistance to macrolides and lincosamides in some countries have increased in the last decade, with some geographic variations and the possibility of inadequate prophylaxis in these patients, so that it is necessary to maintain epidemiological surveillance.

The rates of resistance to macrolides have increased uninterruptedly since the 1990 s, so authors such as Campelo et al. ${ }^{45}$ insist on close monitoring of their evolution. These findings lead us to suggest that laboratories should consider using the D-test to contribute to appropriate treatment of patients who require it.

It is important to remember that the detection of phenotypes is beneficial to the installation of the intrapartum antibiotic prophylaxis, since the existence of the phenotype $\mathrm{iMLS}_{\mathrm{B}}$ reveals the risk of resistance to CLI.

Our results suggest that those pregnant women with intolerance to penicillin should receive adequate antibiotic prophylaxis according to the resistance patterns in the region. Therefore, knowledge of the phenotypes and their patterns of resistance to ERI and CLI prevalent in a region is essential for adequate surveillance and appropriate procedures in the control and prevention of infection. This knowledge also facilitated the selection of strains in the search for resistance genes in this work. The CLSI recom- mends confirmation by MIC of macrolide resistance phenotypes detected by diffusion.

Our results are similar to Pinheiro et al. ${ }^{46}$ in the confirmation by MIC of these phenotypes. However, they differ in that, these investigators found high levels of ERI and CLI resistance with MIC results between 128 and 256 and $\geq 32 \mu \mathrm{g} / \mathrm{mL}$, respectively, in the nine isolates with the $\mathrm{cMLS}_{\mathrm{B}}$ resistance phenotype and three isolates with an $\mathrm{iMLS}_{\mathrm{B}}$ resistance phenotype with MIC for ERI in the range of $16-256 \mu \mathrm{g} / \mathrm{mL}$.

Our findings can be compared with authors such as Schoening et al., ${ }^{47}$ who described only $14.3 \%$ isolates with $\mathrm{iMLS}_{\mathrm{B}}$ resistance phenotype, showing CLI resistance by MIC determination. That is, the inducible resistance to CLI detected by diffusion is not always accompanied by the detection of resistance by MIC, which highlights, even more, the importance of detection of this mechanism of resistance by phenotypic methods.

The detection of genes associated with macrolide resistance in susceptible strains by D-test, followed by confirmation by MIC, allows us to infer its probable expression in the presence of environmental stimuli not yet known in GBS. This bacterium has a recognized capacity to acquire resistance genes from the cervicovaginal and rectal environments.

In this study, we found a close correlation between phenotype and genotype, except for the inducible resistance cases that did not present the ermTR gene. In addition, our data are comparable with the results obtained by other authors where the isolates presenting the $\mathrm{cMLS}_{\mathrm{B}}$ phenotype were mainly associated with the $\operatorname{ermB}$ gene, while those with $\mathrm{iMLS}_{\mathrm{B}}$ or $\mathrm{M}$ phenotype harbored the ermTR gene. ${ }^{48}$ These results are similar to Campelo et al., ${ }^{45}$ who found a total correlation between phenotype and genotype.

Our findings differ from Wang et al., ${ }^{49}$ who detected macrolide resistance rates higher than those presented in this study. However, we agree with the fact that the $c M L S_{B}$ phenotype is predominant and with the detection of the erm $B$ gene in all resistant strains. The $\mathrm{cMLS}_{\mathrm{B}}$ prevalence pattern is homogeneous in several European and American series, although the frequency of resistance varies between $8 \%$ and $38 \%$. ${ }^{45}$

Our studies demonstrate that the $\mathrm{CMLS}_{\mathrm{B}}$ phenotype is associated with either the $e r m B$ or the ermTR gene. This finding suggests that, in some strains of GBS, the ermTR gene has mutated in such a way that it is constitutively expressed. ${ }^{50}$ There were reports of treatment failure in infections due to the appearance of constitutively resistant mutants. ${ }^{47}$ It is recommended that microorganisms with the $\mathrm{iMLS}_{\mathrm{B}}$ phenotype should not be treated with macrolides or lincosamides.

In this study, resistance to $\mathrm{iMLS}_{\mathrm{B}}$ was associated with the ermTR gene. In general, some authors ${ }^{51}$ have reported that isolates with the $\mathrm{iMLS}_{\mathrm{B}}$ phenotype had moderately high MICs to ERI and MIC to CLI in the susceptible category. Strains with the $\mathrm{iMLS}_{\mathrm{B}}$ resistance mechanism may show susceptibility to CLI in vitro by diffusion tests or determination of MIC, but resistance can be detected by PCR for the ermTR gene or a positive D-test.

It is important to note that there may be resistant strains detected by phenotypic methods and the absence of genes associated with resistance, a situation that can be related to the variety of genetic mechanisms that can be linked with a resistance phenotype. In this research, the presence of the 
most reported genes was determined, although there are other less frequent resistance-determining genes such as erm $C$, ermF, erm $Q$, ermT, msrA, or $m s r D$, all described for streptococci. ${ }^{52}$ In addition, mutations in $23 \mathrm{~S}$ rRNA or genes encoding ribosomal proteins may also result in possible causes of ERI resistance in such strains.

The genes associated with macrolide resistance, such as ermB, ermTR, and mefA, as well as other resistance genes to other antimicrobial agents, are found on mobile elements such as plasmids and/or transposons. These genes, mediated by horizontal transfer, can pass among organisms being widely disseminated, with consequences not only for a region but also beyond its borders. This gene transfer further supports the need for the permanent monitoring of resistance to phenotypically and genotypically characterized strains, which will also help our understanding of the acquisition of new resistance mechanisms. ${ }^{35}$

We agree with other authors ${ }^{53}$ that susceptible strains that carry some of the resistance genes detected may begin to express them under certain unknown environmental stimuli. This is an important factor in GBS because it has a recognized ability to acquire resistance genes from the cervicovaginal and rectal environment. The increase and spread of resistance to macrolides and lincosamides, both in GBS and in other species of streptococci, have already had implications in therapeutics and prophylaxis.

The high transmissibility of hemolytic streptococci, including those of macrolide-resistant clones, and the high frequency of use of antibiotics may be responsible for the marked increase in resistance reported in the last decade. ${ }^{36}$ The World Health Organization recommends the monitoring of antimicrobial susceptibility, including macrolides and lincosamides, as well as epidemiological studies, including surveillance of the dissemination of clonal strains carrying resistance.

Previous studies on GBS suggest that the RAPD is an epidemiological technique superior to serotyping for the evaluation of this pathogen. This technique has the advantage of being able to differentiate the strains within a specific serotype. Our results coincide with Martínez et al. ${ }^{28}$ and show that a correlation in serotype and different RAPD patterns cannot be established.

These results indicate that classification based on serological traits, traditionally used for epidemiological investigations, may not reflect the clonal relationships between GBS isolates. This observation supports the idea that the RAPD might be more successful than serotyping in the differentiating of the GBS strains because it is fast, easy to perform, and useful in routine epidemiological investigations. ${ }^{54}$ Moreover, these epidemiological studies will be greatly benefited by the discriminatory power of molecular techniques, which is higher with respect to phenotypic typing methods.

Zhang et al. ${ }^{54}$ support the RAPD technique for epidemiological purposes because the isolates are tested in duplicate or triplicate, and only the amplicons occurring in both cases are taken into consideration. In addition, the technique was performed with an interval of 12 months and the results obtained were similar in all cases.

In this research, the discrimination index obtained using OPS11 primer was equal to one, which emphasizes its utility and ability to discriminate between nongenetically related isolates. Our results show that genetic diversity exists not only between different serotypes but also within a given se- rotype. The resistance to macrolides in the province of Misiones is due to a multiclonal spread since the distance obtained between the different isolates was in all cases $>47 \%$.

In addition, the groupings, although distant, showed no relationship with the serotype or with the resistance phenotype observed. Similar percentages of phenotypes $\mathrm{cMLS}_{\mathrm{B}}$ and $\mathrm{iMLS}_{\mathrm{B}}$ were observed by Brzychczy-Włoch et al., ${ }^{55}$ who concluded that the dissemination resistance was due to both clonal dissemination and horizontal transmission between strains. This does not coincide with the results obtained by Campelo et al., ${ }^{45}$ where it was observed that $67.9 \%$ of the $\mathrm{MLS}_{\mathrm{B}}$ strains are grouped into four clones. This information is of the utmost importance when monitoring the emergence of new resistant strains since it can lead to the selection of more reasonable and effective therapies.

A detailed genetic analysis of the different strains isolated from GBS in other regions of the country and of the world could contribute to a better understanding of the biological diversity and epidemiological aspects involved in the transmission of diseases caused by GBS.

To date, no information has been found in similar studies at the regional level, which encourages the continuation of our research to contribute to the knowledge of resistance in GBS and to collaborate with the prevention and improvement of the treatment of these infections.

The importance of the phenotypic and genotypic characterization of macrolide resistance in GBS strains is crucial to contribute to the intrapartum prophylactic antibiotic therapy of allergic pregnant women, to the epidemiological surveillance of these strains, and to the knowledge of the distribution and frequency of their appearance as a prerequisite for the design of vaccine strategies. ${ }^{56}$

We emphasize the importance of the implementation of a control program of maternal colonization by GBS between 35 and 37 weeks of gestation, combining serotyping and RAPD patterns for the study of this microorganism, as well as the use of an intrapartum treatment regimen in $100 \%$ of cases in which infection has been detected.

It is important to highlight the need to continue similar studies that allow the epidemiological surveillance of circulating serotypes and the carrying and expression of resistance genes in GBS strains to contribute to the study of GBS disease and prevent its outcome in newborns. Epidemiological surveillance of the susceptibility of GBS to penicillin and other antimicrobials of choice such as macrolides in $\beta$-lactam allergic patients is necessary to ensure adequate treatments and to detect new resistance mechanisms or strains with decreased susceptibility.

\section{Disclosure Statement}

No competing financial interests exist.

\section{Funding Information}

No funding was received for this article.

\section{References}

1. Baker, C. 2000. Group B streptococcal infections. In E. Kaplan and D. Stevens (ed.), Streptococcal infections. clinical aspects, microbiology and molecular pathogenesis. Oxford, United Kingdom: Oxford University Press, pp. 222-237. 
2. Fry, R. 1938. Fatal infections by haemolytic Streptococcus group B. Lancet 1:199-201.

3. Schuchat, A. 1998. Epidemiology of group B streptococcal disease in the United States: shifting paradigms. Clin. Microbiol. Rev. 11:497-513.

4. Arias, B., V. Kovacec, L. Vigliarolo, M. Suárez, C. Tersigni, L. Müller, H. Lopardo, L. Bonofiglio, and M. Mollerach. 2019. Fluoroquinolone-resistant Streptococcus agalactiae invasive isolates recovered in Argentina. Microb. Drug Resist. 25:739-743.

5. Biondi, E, R. Evans, M. Mischler, M. Bendel-Stenzel, S. Horstmann, and V. Lee. 2013. Epidemiology of bacteremia in febrile infants in the United States. Pediatrics 132: 990-996.

6. Vergadi, E., A. Manoura, E. Chatzakis, E. Karavitakis, S. Maraki, and E. Galanakis. 2018. Changes in the incidence and epidemiology of neonatal group B Streptococcal disease over the last two decades in Crete, Greece. Infect. Dis. Rep. 10:7744.

7. Winn, W., S. Allen, W. Janda, E. Koneman, G Procop, and P. Schreckenberger. 2006. Koneman's Color Atlas and Textbook of Diagnostic Microbiology, 6th ed. Philadelphia, PA: Lippincott Williams \& Wilkins, pp. 639-727.

8. Martínez, M., A. Ovalle, C. Durán, I. Reid, G. Urriola, and B. Garay. 2004. Serotypes and antimicrobial susceptibility of Streptococcus agalactiae. Rev. Med. Chil. 132:549-555.

9. Lindahl, G., M. Stalhammar-Carlemalm, and T. Areschoug. 2005. Surface proteins of Streptococcus agalactiae and related proteins in other bacterial pathogens. Clin. Microbiol. Rev. 18:102-127.

10. Verani, J., L. McGee, and S. Schrag. 2010. Prevention of perinatal group B streptococcal disease. MMWR Recomm. Rep. 59:1-32.

11. Kimura, K., S. Suzuki, J. Wachino, H. Kurokawa, K. Yamane, N. Shibata, N. Nagano, H. Kato, K. Shibayama, and Y. Arakawa. 2008. First molecular characterization of group B streptococci with reduced penicillin susceptibility. Antimicrob. Agents Chemother. 52:2890-2897.

12. Portillo, A., M. Lantero, I. Olarte, F. Ruiz-Larrea, and C. Torres. 2001. MLS resistance phenotypes and mechanisms in beta-haemolytic group B, C and G Streptococcus isolates in La Rioja, Spain. J. Antimicrob. Chemother. 47: 115-116.

13. Bolukaoto, J., C. Monyama, M. Chukwu, S. Lekala, M. Nchabeleng, M. Maloba, R. Mavenyengwa, S. Lebelo, S. Monokoane, C. Tshepuwane, and S. Moyo. 2015. Antibiotic resistance of Streptococcus agalactiae isolated from pregnant women in Garankuwa, South Africa. BMC Res. Notes 20:364.

14. Dutra, V., V. Alves, A. Olendzki, C. Dias, A. de Bastos, and G. Santos. 2014. Streptococcus agalactiae in Brazil: serotype distribution, virulence determinants and antimicrobial susceptibility. BMC Infect. Dis. 14:323.

15. Clinical and Laboratory Standards Institute. 2017. Performance Standards for Antimicrobial Susceptibility Testing. 27th Informational Supplement, 2017; M100. EE.UU, Wayne, PA.

16. Tamariz Ortiz, J., J. Cruz Quintanilla, A. Atencia Porras, J. Figueroa Tataje, G. Horna Quintana, and H. Guerra Allison. 2009. Erythromycin-Induced Clindamycin Resistance in Staphylococcus aureus Isolated from Three Hospitals in Lima, Peru [in Spanish]. Acta Med. Peruana 26:12-16.

17. Limansky, A., E. Sutich, M. Guardati, I. Toresani, and A. Viale. 1998. Genomic diversity among Streptococcus agalactiae isolates detected by a degenerate oligonucleotideprimed amplification assay. J. Infect. Dis. 177:1308-1313.

18. Lin, T., L. Lin, and F. Zhang. 2014. Review on molecular typing methods of pathogens. Open J. Med. Microbiol. 4: 147-152.

19. Williams, J., A. Kubelik, K. Livak, J. Rafalski, and S. Tingey. 1990. DNA polymorphisms amplified by arbitrary primers are useful as genetic markers. Nucleic Acids Res. 18:6531-6535.

20. Oviedo, P., E. Pegels, M. Laczeski, M. Quiroga, and M. Vergara. 2013. Phenotypic and genotypic characterization of Streptococcus agalactiae in pregnant women. First study in a province of Argentina. Braz. J. Microbiol. 44:253-258.

21. Laczeski, M., M. Novosak, and M. Vergara. 2016. Five years' experience in conservation of Streptococcus agalactiae: comparison of two alternative methodologies. Rev. Cien. Tecnol. 25:11-14.

22. Poyart, C., A. Tazi, H. Réglier-Poupet, A. Billoët, N. Tavares, J. Raymond, and P. Trieu-Cuot. 2007. Multiplex PCR assay for rapid and accurate capsular typing of group B streptococci. J. Clin. Microbiol. 45:1985-1988.

23. Rozen, S., and H. Skaletsky. 2000. Primer3 on the WWW for general users and for biologist programmers. In S. Krawetz and S. Misener (ed.), Bioinformatics methods and protocols: methods in molecular biology. Humana Press, Totowa, NJ, pp. 365-386.

24. Sambrook, J., and D. Rusell. 2001. Molecular Cloning: A Laboratory Manual. New York: Cold Spring Harbor, pp. 1-3.

25. Cariaga Martinez, A., and P. Zapata. 2007. The Molecular Biology Laboratory. Posadas, Mexico: Editorial Universitaria de Misiones, pp. 23-39.

26. Corso, A., D. Faccone, P. Gagetti, J. Pace, and M. Regueira. 2009. Prevalence of mef and ermB genes in invasive pediatric erythromycin-resistant Streptococcus pneumoniae isolates from Argentina. Rev. Argent. Microbiol. 41:29-33.

27. Faccone, D., F. Lalonardi, S. Abel, M. Machain, L. Errecalde, and A. Littvik. 2010. Multiple-.lones of Streptococcus agalactiae harbouring $\ln u B$ gene. J. Infect. Dev. Ctries. 4:580-582.

28. Martinez, G., J. Harel, R. Higgins, S. Lacouture, D. Daignault, and M. Gottschalk. 2000. Characterization of Streptococcus agalactiae isolates of bovine and human origin by randomly amplified polymorphic DNA analysis. J. Clin. Microbiol. 38:71-78.

29. Hunter, P., and M. Gaston. 1988. Numerical index of the discriminatory ability of typing systems: an application of Simpson's index of diversity. J. Clin. Microbiol. 26:24652466.

30. Lopardo, H., P.Vidal, P. Jeric, D. Centron, H. Paganini, and R. Facklam. 2003. Six-month multicenter study on invasive infections due to group B streptococci in Argentina. J. Clin. Microbiol. 41:4688-4694.

31. Souza, V., F. Kegele, S. Souza, F. Neves, G. de Paula, and R. Barros. 2013. Antimicrobial susceptibility and genetic diversity of Streptococcus agalactiae recovered from newborns and pregnant women in Brazil. Scand. J. Infect. Dis. 45:780-785.

32. Abarzúa, C., E. Arias, C. García, T. Ralph, L. Cerda, K. Riedel, and O. Gárate. 2011. Streptococcus agalactiae increase in resistance to erythromycin and clindamycin in vaginal-anal colonization in third quarter of pregnancy in one decade of universal screening. Rev. Chil. Infect. 28:334-337. 
33. Back, E., E. O'Grady, and J. Backa. 2012. High rates of perinatal group B Streptococcus clindamycin and erythromycin resistance in an upstate New York Hospital Ephraim. Antimicrob. Agents Chemother. 56:739-742.

34. López, Y., E. Parra, V. Cepas, I. Sanfeliú, T. Juncosa, A. Andreu, M. Xercavins, J. Pérez, S. Sanz, A. Vergara, J. Bosch, and S. Soto. 2018. Serotype, virulence profile, antimicrobial resistance and macrolide-resistance determinants in Streptococcus agalactiae isolates in pregnant women and neonates in Catalonia, Spain. Enferm. Infecc. Microbiol. Clin. 36:472-477.

35. Wang, Y., C. Chen, J. Hou, Y. Wang, T. Lin, M. Wang, T. Yang, C. Chu, and C. Chiu. 2015. Serotype distribution and resistance genes associated with macrolide and fluoroquinolone resistance in Streptococcus agalactiae isolates from a hospital in Southern Taiwan. Biomed. J. 38:215-220.

36. Lee, B., Y. Song, M. Kim, J. Yang, J. Shin, Y. Seo, K. Oh, H. Yoon, S. Pai, B. Foxman, and M. Ki. 2010. Epidemiology of group B Streptococcus in Korean pregnant women. Epidemiol. Infect. 2:292-298.

37. Savoia, D., C. Gottimer, C. Crocilla, and M. Zucca. 2008. Streptococcus agalactiae in pre gnant women: phenotypic and genotypic characters. J. Infect. 56:120-125.

38. Fröhlicher, S., G. Reichen-Fahrni, M. Müller, D. Surbek, S. Droz, and B. Spellerberg. 2014. Serotype distribution and antimicrobial susceptibility of group B streptococci in pregnant women: results from a Swiss tertiary centre. Swiss Med. Wkly. 144:w13935.

39. Elliott, J., K. Farmer, and R. Facklam. 1998. Sudden increase in isolation of group B streptococci, serotype $\mathrm{V}$, is not due to emergence of a new pulsed-field gel electrophoresis type. J. Clin. Microbiol. 36:2115-2116.

40. Gherardi, G., M. Imperi, L. Baldassarri, M. Pataracchia, G. Alfarone, S. Recchia, G. Orefici, G. Dicuonzo, and R. Creti. 2007. Molecular epidemiology and distribution of serotypes, surface proteins, and antibiotic resistance among group B streptococci in Italy. J. Clin. Microbiol. 45:29092916.

41. Le Thomas-Bories, I., F. Fitoussi, P. Mariani-Kurkdjian, J. Raymond, N. Brahimi, and P. Bidet 2001. Clonal relationship between U.S. and French serotype V group B Streptococcus isolates. J. Clin. Microbiol. 39:4526-4528.

42. Chohan, L., L. Hollier, K. Bishop, and C. Kilpatrick. 2006. Patterns of antibiotic resistance among group B Streptococcus isolates: 2001-2004. Infect. Dis. Obstet. Gynecol. 2006:574-592.

43. Manning, S. 2003. Molecular epidemiology of Streptococcus agalactiae (group B Streptococcus). Front. Biosci. $1: 1-18$.

44. Wu, B., J. Su, L. Li, W. Wu, J. Wu, Y. Lu, W. Li, J. Cheng, and X. Liang. 2019. Phenotypic and genetic differences among group B Streptococcus recovered from neonates and pregnant women in Shenzhen, China: 8-year study. BMC Microbiol. 19:185.

45. Campelo, F., A. Pedrosa, I. Antúnez, and B. Capuz. 2012. Phenotypes and mechanisms of resistance to macrolides and lincosamides in Streptococcus agalactiae isolates with clinical significance in an eight-year period (2002-2010). Rev. Esp. Quimioter. 25:42-46.

46. Pinheiro, S., H. Radhouani, C. Coelho, A. Gonçalves, E. Carvalho, and J. Carvalho. 2009. Prevalence and mechanisms of erythromycin resistance in Streptococcus agalactiae from healthy pregnant women. Microb. Drug Resist. 15:121-124.

47. Schoening, T., J. Wagner, and M. Arvand. 2005. Prevalence of erythromycin and clindamycin resistance among Streptococcus agalactiae isolates in Germany. Clin. Microbiol. Infect. 11:579-582.

48. Nakamura, P., R. Schuab, F. Neves, C. Pereira, G. Paula, and R. Barros. 2011. Antimicrobial resistance profiles and genetic characterisation of macrolide resistant isolates of Streptococcus agalactiae. Mem. Inst. Oswaldo Cruz 106: 119-122.

49. Wang, P., Z. Ma, J. Tong, R. Zhao, W. Shi, S. Yu, K. Yao, Y. Zheng, and Y. Yang. 2015. Serotype distribution, antimicrobial resistance, and molecular characterization of invasive group B Streptococcus isolates recovered from Chinese neonates. Int. J. Infect. Dis. 37:115-118.

50. Emaneini, M., A. Mirsalehian, R. Beigvierdi, A. Fooladi, F. Asadi, F. Jabalameli, and M. Taherikalani. 2014. High incidence of macrolide and tetracycline resistance among Streptococcus agalactiae strains isolated from clinical samples in tehran, Iran. Maedica (Buchar) 9:157-161.

51. Panagea, S., J. Perry, and F. Gould. 1999. Should clindamycin be used as treatment of patients with infections caused by erythromycin-staphylococci? J. Antimicrob. Chemother. 44:581-582.

52. Roberts, M. 2008. Update on macrolide-lincosamidestreptogramin, ketolide, and oxazolidinone resistance genes. FEMS Microbiol. Lett. 282:147-159.

53. Ardanuy, C., F. Tubau, J. Liñares, M. Domínguez, R. Pallarés, and R. Martín. 2005. Distribution of subclasses $m e f A$ and mefE of the mefA gene among clinical isolates of macrolide-resistant (M-phenotype) Streptococcus pneumoniae, Viridans group streptococci, and Streptococcus pyogenes. Spanish Pneumococcal Infection Study Network. Antimicrob. Agents Chemother. 49:827-829.

54. Zhang, G., M. Kotiw, and G. Daggard. 2002. A RAPD-PCR genotyping assay which correlates with serotypes of group B streptococci. Lett. Appl. Microbiol. 35:247-250.

55. Brzychczy-Włoch, M.,T. Gosiewski, D. Pawlik, A. Szumała-Kakol, A. Samead, and P. Heczko. 2012. Occurrence of the hypervirulent ST-17 clone of Streptococcus agalactiae in pregnant women and newborns. Przegl. Epidemiol. 66:395-401.

56. Chen, V., F. Avci, and D. Kasper. 2013. A maternal vaccine against group B Streptococcus: past, present, and future. Vaccine 31:13-19.

Address correspondence to:

Margarita Laczeski, PhD

Associate Professor of Bacteriology

Microbiology Department

Institute of Biotechnology Misiones

"Dra. María Ebe Reca" (InBioMis)

Faculty of Exact, Chemical

and Natural Sciences (FCEQyN)

National University of Misiones (UNaM)

Research Associate of the CONICET (National Council

for Scientific and Technical Research)

Avda. Mariano Moreno 1375, Posadas

Misiones CPA N3300LQH

Argentina

E-mail: mlaczeski@gmail.com 